
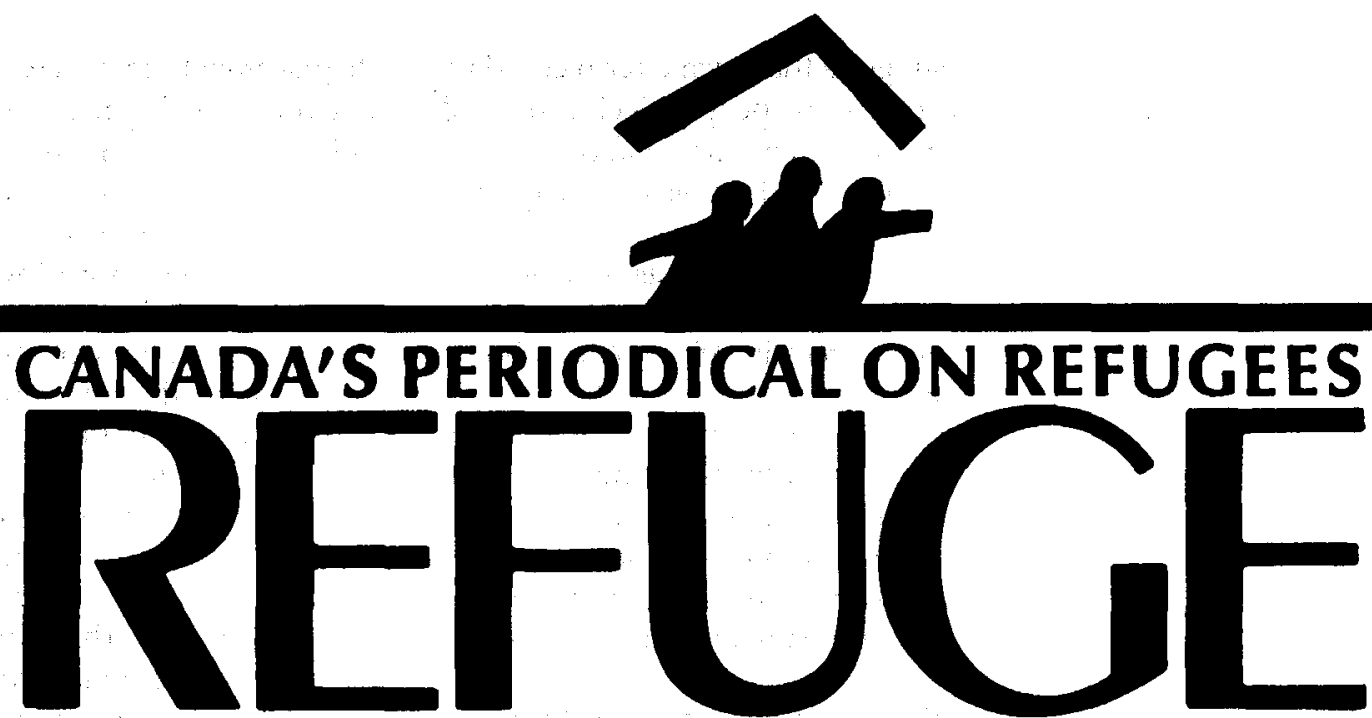

Vol. 12, No. 1

\title{
SPECIAL ISSUE ENVIRONMENTAL REFUGEES
}

This is the first Refuge issue devoted to "Environmental Refugees." We are pleased to present a collection of articles that deal with environmental problems in a wide range of countries across four continents, particularly Asia. In these articles, the approaches to the topic as well as the styles of writing vary a great deal. This editorial introduces some of the important issues raised by the contributors, as well as adding to the debate.

\section{From Natural Disasters To Ecocide}

We have tried to present these articles in a logical progression, going from a discussion of refugees fleeing natural disasters to those displaced by humanmade causes, i.e. dams and other development schemes, and finally to those who are the victims of intentional environmental degradation or "ecocide."

In discussing the people of Bangladesh fleeing their homelands after they have been devastated by cyclones and tidal surges, Muinul Islam employs the term "ecological refugees."

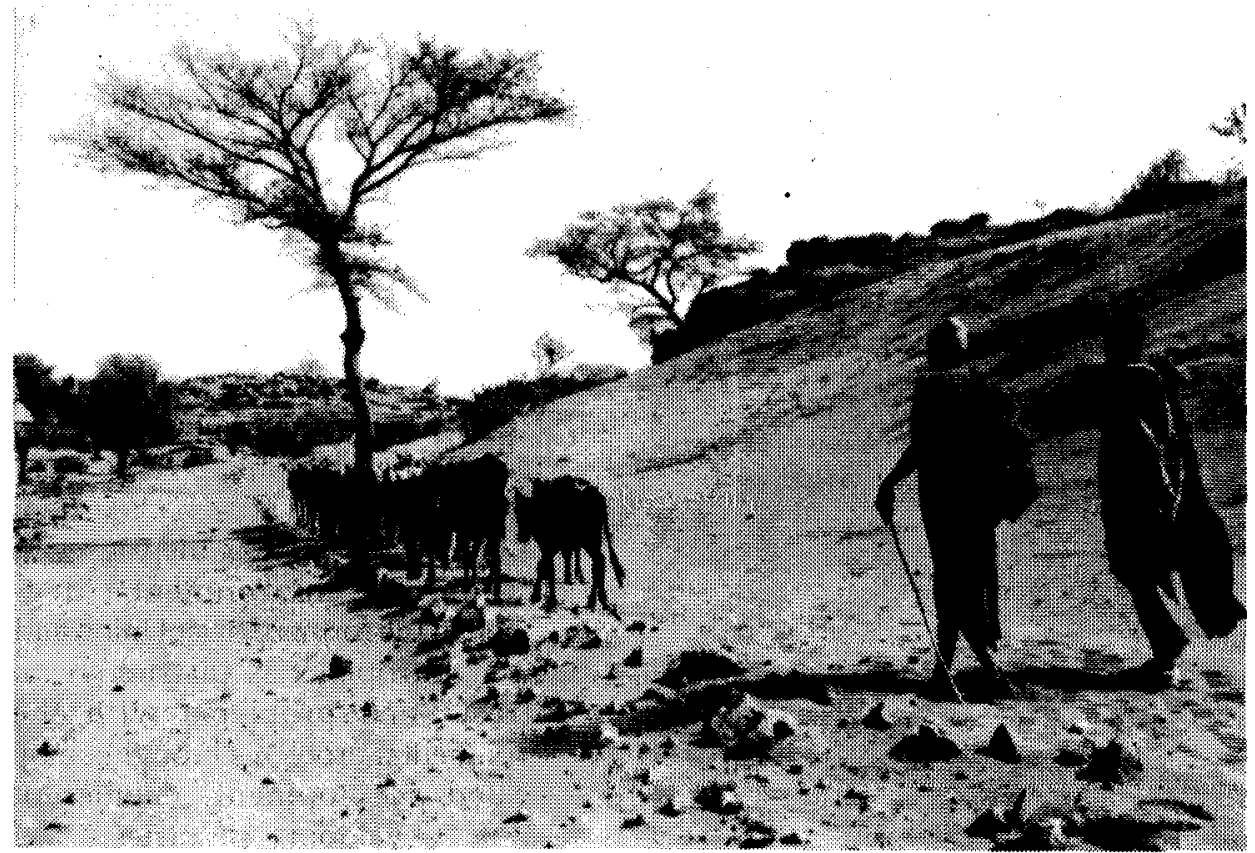

PHOTO; V. LASSAILLY-JACOB 


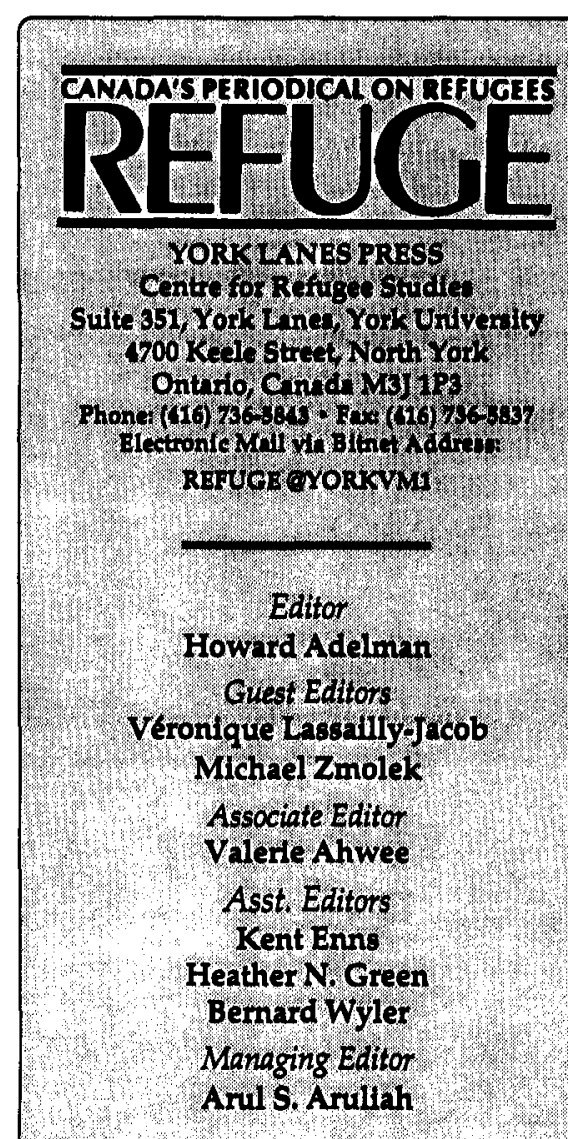

Refige is dedicated to the encouragement of assistance to refugees by providing a forum for sharing in. formation and opinion on Canadian and international issues pertaining to refugees:

It Is published ten tmes a year by York Lanes Press for the Centre for Refugee Studies, York University. Canada. Refuge is a nonprofit, independent periodical supported by private donations and by subsciptions? itis a forum for discisilon, and the views expresseddo not necessarily reflect those of its funders or staff.

Ail material In Refuge nay be re. produced without permission unless copyrighted or otherwise indicated. Credit should be given to the author or source, If named, and Refuge, Sub. missions on related issues are welcome for publication consideration.

Current subscription rates for one year (ten issues) are:

Canada Can $\$ 50.00$

All other countries U,S. 560.00

Single issues are avallable at $\$ 6,50$ per copy.

Please enclose payment made pay. able to York Lanes Press, with your order.

ISSN 0229.5113
This suggests that such a term could be used to refer to people fleeing natural disasters such as earthquakes, hurricanes, floods, volcanic eruptions and the like.

Ogenga Otunnu takes a theoretical approach to the question of environmental refugees in Africa. Africa holds only about ten percent of the world's population, but nearly twenty five percent of its refugees. He discusses the wide variety of environmental problems in Africa and various attempts to alleviate the recurrent suffering. He cites the Food and Agricultural Organization (FAO) and various well-known scholars who view the problem as basically one of overpopulation and misuse of land, arguing against such an explanation "which reduces the causes and persistence of the crisis to individuals and fails to understand the conditions under which the crisis occurs [and which] is a false comfort since it cannot lead to appropriate actions."

In presenting a broad overview of pollution, hazardous waste and the devastation of Chernobyl in the Commonwealth of Independent States (CIS), Renate Rybizki talks of regions under "critical ecological situations." She raises the issue of finding "ecologically clean" regions for the resettlement of persons currently living in "unclean" regions, which now comprise twenty percent of the former USSR. Hence, this enormous problem appears to be insoluble. While rapid industrialization and poor management have often been cited as the causes of pollution and environmental degradation in the former Soviet Union and Eastern Europe, it is instructive to contrast such problems with the environmental problems brought on by so-called development schemes in various "developing countries." The three pieces that follow Rybizki look at the effects of development, including the case of communist China. The term that is sometimes heard in labelling the people ousted by such projects is "developmental refugees."

The Friends of the Earth from Malaysia give us a broad overview of many different types of "environmental displacement" in Malaysia. Industrialization, development schemes and subsequent land speculation have resulted in a plethora of environmental catastrophes for rural and indigenous peoples, often resulting not only in displacement, but repeated displacement. The authors of this piece work closely with the affected communities and so they try to integrate those views into their critique.

A similar approach is employed by Dave Hubbel and Noel Rajesh, who review the plans for eucalyptus tree plantations by the government of neighbouring Thailand, "which is forcibly evicting over ten million people from the country's National Forest Reserves." This figure is nearly a fifth of that country's population. The authors write: "The eviction programme has been shoddily formulated and callously implemented without regard for the welfare of village people."

Joseph Whitney examines the proposal to build the Three Gorges Dam. on the Yangtse River in China. The dam will be the largest single hydro project ever and will displace between 539,000 and 1.2 million people (depending on the water level that is set). He concludes that a large number of costs have not been perceived or evaluated in the resettlement proposal and suggests that "the symbolic benefits of large dams have a nonmonetary value that is perceived to exceed all other costs." Hence the real costs in human, environmental and even monetary terms may be disregarded.

We turn now from cases where dislocation is the residual or prearranged consequence of development projects to cases of war. Jim Glassman writes of Vietnam and Cambodia, where massive bombing was employed, forcing peasants to flee to the cities. Glassman asserts that "ecological destruction has become integrated into counterinsurgency as a method of producing the refugees necessary for effective control of the countryside by imperial powers and their allies." He employs the term "ecocide" to describe the intentional destruction of the enemy's environment, citing the massive use of herbicides by 
the U.S. military in Vietnam (as much as 41 percent of South Vietnam's mangrove forests were denuded) and the destruction of Salvadoran forests by napalm and other defoliants.

Destroying the environment is alsoa way of preventing refugees from coming back to their homeland. According to John Rogge, the Iraqi army sowed mines along roads, in orchards and in vineyards, around springs and wells and along mule tracks in order to terrorize the Kurdish population and discourage them from returning to their villages.

Moreover, it can easily be overlooked that environmental degradation can be a secondary consequence of either a development project or strategic destruction. Such residual effects may produce migrants or refugees. For example, the construction of a dam in a densely populated river valley may have a devastating impact on millions of downstream residents if their production systems are dependent in large part on annual flood recession. Glassman notes that in Vietnam the "flooding of rice lands continues to be a major problem because so many hillsides are denuded of foliage that rainfall is not absorbed adequately and rushes down onto the plains."

\section{Environmental Refugees: The Value of a Category}

An environmental refugee is often defined as someone fleeing from environmental decline. However, a recent article by Astri Suhrke and Annamaria Visentin* criticizes this definition in that: "It is so wide as to render the concept virtually meaningless." And rather than shy away at this juncture, the authors decide to forge ahead and define the term. "Uncritical definitions and inflated numbers lead to inappropriate solutions and compassion fatigue. We should not, however, reject outright the concept of environmental refugees. Instead we should formulate a definition that is more narrow but [sic] more precise."

\footnotetext{
"Astri Suhrke and Annamaria Visentin, "The Environmental Refugee: A New Approach," Ecodecision (September 1991): 73-74.
}

They proceed to make a distinction between environmental refugees and environmental migrants. The latter is someone who "makes a voluntary, rational decision to leave a region as the situation gradually worsens there," a decision that may be only partly based on environmental factors. She/he "moves by choice from an area." Juxtaposed against this is the definition of environmental refugees: "people or social groups displaced as a result of sudden, drastic environmental change that cannot be reversed." They are compelled to flee.

The distinction appears to be merely one of time. But the authors elaborate that the difference is between the truly desperate (and vulnerable) who cannot expect support from their own governments and are therefore refugees,

\section{"...[T]here is a danger that we will begin to invent new categories simply by divorcing them from other categories and create hierarchies of terms by which people are somewhat arbitrarily classified."}

and those with more resources, contacts and the time to plan for their migration. Suhrke and Visentin admit that "the separation is not absolute between the categories ... there may be a shading between the two." These authors are concerned primarily with distributing relief aid and hence the problem arises of how to categorize the various types of beneficiaries according to their needs. However, such a distinction is vague. It does not help us to understand the relationship the two groups have to each other and to the rest of the social groups in the society. It also does not confront political questions directly. It needs to be asked: Were the peopleinvolved coerced or not coerced to move? Did they have any say in the political process that may have resulted in the decision that they would be evicted/resettled? Does the religious, ethnic, gender or age group to which these persons belong suffer any forms of discrimination or marginalization in the society? Without adequately addressing the socio-political, economic and historical dimensions for each specific regional problem, there is a danger that we will begin to invent new categories simply by divorcing them from other categories and create hierarchies of terms by which people are somewhat arbitrarily classified.

Suhrke and Visentin's distinction between environmental migrant and environmental refugee is thus an attempt to place particular emphasis on the most desperate of the population and to promote them to the status of "refugee." Yet such attempts to employ the term "refugees," as well as attempts to designate people ousted by development projects as "developmental refugees," or persons forced to abandon their lands due to war as "war refugees," are counter-productive and simply run up against the blinkered $U N$ definition of refugee, which requires the crossing of international borders.

Writing of people in Bangladesh fleeing their homelands devastated by natural disasters, Muinul Islam mentions that "ecological refugees" in Bangladesh lose sympathetic public attention after the initial media attention subsides and the official relief camps are closed down. "Conceptually, these refugees are variously termed as "economic migrants," "distress migrants," or "compelled migrants," but the compulsive push of circumstances becomes so much a matter of life and death for the refugees fleeing the ravages of natural disasters that normally they have no choice but to migrate. Therefore, the term refugee should be more appropriate than the term migrant." Islam would like the victims of natural disasters in Bangladesh to receive the same sorts of comprehensive assistance that many cross-border refugees receive. He argues that the concept of a refugee has been stereotyped as someone fleeing the ravages of war, civil strife, political repression, famine or disease. The debate on famine aside, none of these causes necessarily involve an ecological dimension. 
In discussing the complex problems of environment, poverty, war and the like in Africa, Ogenga Otunnu points out that environmental degradation is both a cause and an effect of poverty. He argues "the nature of the neo-colonial states and the international economic system must be overhauled." Poverty cannotbeleft as a problem for individual governments in Africa to deal with because many larger issues are involved. Therefore he urges that the UN should begin to recognize environmental refugees as refugees and act accordingly.

\section{Problems of Rellef and Assistance for "Refugees"}

The United Nations definition of a refugee requires that the person cross international borders and be able to prove that she/he suffers from religious, ethnic or political discrimination in order to be recognized as such. Migrants, or "internally displaced persons" are therefore people who migrate within their own country. This distinction is problematic in many ways. In particular it is a problem with the concept of nation states, in that other nations may be asked to step in and assist people who have crossed borders, thus sparing the host nation some of the cost of assisting such people.

Environmental refugees are often people who migrate within their own country. They are "internally displaced persons" who, except in particular cases of acute distress, are left to the mercy of their own governments - governments that may be oppressive, or even the cause of their migration. But relief given to persons affected by disasters and who remain within their own countries normally involves only short-lived projects.

People displaced by development are often promised adequate compensation (though they may have had no say in the decision to move). Compensation and plans for

Véronique Lassailly-Jacob is a visiting Research Fellow and Michael Zmolek is a Research Assistant at the Centre for Refugee Studies, York University. resettlement often involve corruption and leave people in a much worse condition than before their displacement. Thus in Thailand, 250,000 families evicted from their land will be resettled on "an area of land one-quarter the size of that from which they once sustained themselves. Of this area, land suitable for agriculture is often already owned and farmed by other villages" (Hubbel \& Rajesh). And in Malaysia, the resettlement of 3,000 Iban natives who, instead of the 11 acres of cleared land that they had been promised per family,

"Formulating definitions
that can be useful as
conceptual tools is clearly
necessary, but there is a risk
of developing hierarchies
that may be used for political
manipulation and bring
about nightmarish
difficulties for people trying
to find refuge."

received only one acre. Furthermore, Sahabat Alam reports that "they had to pay for their new longhouses when they were informed earlier that it would be free."

Finally, it can hardly be expected that the same western governments who are contributing to the increasing numbers of refugees - (a) by funding development projects that displace people, or (b) by waging war against rural insurgencies - to donate tremendous funds to those same refugees. In the case of (a), assistance may be given as part of the resettlement and compensation part of the project, but often such funds are inadequate, or are squandered through corruption; and in the case of (b), we need only consider the case of Vietnam, still suffering the effect of an embargo imposed by the United States.

\section{Conclusion}

The situation of people fleeing environmental or other kinds of devastation demands solutions. Solutions will only be as good as their analysis, planning and implementation. Formulating definitions that can be useful as conceptual tools is clearly necessary, but there is a risk of developing hierarchies that may be used for political manipulation and bring about nightmarish difficulties for people trying to find refuge. Moreover, the academic tradition today demands specialization which precipitates a search for new fields of research and new categories. However, the promulgation of definitions and categories must not overtake the search for real, viable solutions. The misery of others must not be used as simply the domain for carving out a career niche.

Economic refugees, environmental refugees, migrants, internally displaced persons, whatever we call them, all are one in that they are all destitute and oppressed people. Certainly there are degrees of poverty, degrees of oppression and even degrees of environmental degradation, but the solution can only lie in building sound economies, legal structures that safeguard human rights and that minimize environmental degradation, nay more, those that practice regeneration of the environment.

The pieces presented in this issue clearly demonstrate the wide variety of environmental problems that produce "refugees," the hitherto poor attention given to them and the need to more closely examine the environmental factors that lead to their flight in search of refuge. Those factors should not be examined in a closet, however. Rather, environmental factors urgently need to be more clearly incorporated into the agenda - alongside socio-political and economic concerns - of all serious research and analysis in the social sciences and in the "development" field as well. …

Véronique Lassailly-Jacob
Michael Zmolek
Guest Editors

